\title{
AEROMAGNETIC MAP OF THE UXBRIDGE QUADRANGLE, WORCESTER COUNTY, MASSACHUSETTS, AND PROVIDENCE COUNTY, RHODE ISLAND
}

\author{
GEOPHYSICAL INVESTIGATIONS \\ MAP GP-769
}

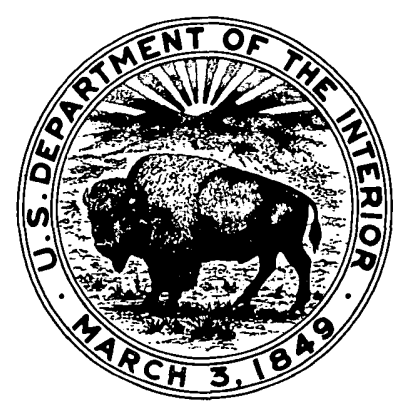

